\title{
Prospective assessment of key factors influencing treatment strategy and outcome of fragility fractures of the pelvis (FFP)
}

\author{
Pol Maria Rommens ${ }^{1}$ (I) $\cdot$ Johannes Christoph Hopf ${ }^{1} \cdot$ Charlotte Arand $^{1} \cdot$ Kristin Handrich $^{1} \cdot$ Mehdi Boudissa $^{1}$. \\ Daniel Wagner ${ }^{1}$
}

Received: 26 November 2021 / Accepted: 17 January 2022 / Published online: 5 February 2022

(c) The Author(s) 2022

\begin{abstract}
Background Fragility fractures of the pelvis (FFP) are a clinical entity with an increasing significance in clinical practice. Little is known about the conditions, which influence decision making and outcome.

Setting Level I trauma center.

Material and methods Prospective assessment of selected parameters of patients, who were admitted with a FFP in a 2-year period. Fractures were classified in accordance with the Rommens and Hofmann classification. Living environment, level of autonomy (independent walking), type of treatment (conservative versus operative), type of surgical technique, European Quality of Life-5 Dimensions-5 Levels (EQ-5D-5L), Short Form-8 Physical Component Score (SF-8 PCS) and Short Form-8 Mental Component Score (SF-8 MCS), Barthel Index, Parker Mobility Score (PMS) and Numeric Rating Scale (NRS) were collected at primary presentation (t1), at discharge (t2) and after 3 (t3) and 12 months (t4). Length of hospital stay, in-hospital complications, surgery-related complications, new osteoporotic fractures and mortality rate within the first year were also registered. The key factors influencing the choice of therapy and outcome were looked for.

Results 110 patients, 99 women (90\%) and 11 men (10\%), were included in the study. Their mean age was 79.2 years (SD 10 years). Fourteen patients had FFP type I (12.7\%), 59 FFP type II (53.6\%), 11 FFP type III (10\%) and 26 FFP type IV fractures (23.6\%). All patients with FFP type I were treated conservatively. 48 patients with FFP types II-IV were treated conservatively and 48 operatively. Patients, who got a conservative outpatient treatment first and were hospitalized later, had higher FFP fracture types at admission. Operatively treated patients were hospitalized at a median of 33.5 days after the beginning of complaints, whereas the median day of admission of the conservative group was the day of trauma $(p<0.001)$. The operatively treated patients were hospitalized in a worse clinical condition (SF-8 PCS, EQ-5D-5L, autonomy). Length of stay $(\mathrm{LoS})$ of operatively treated patients was significantly longer than of conservatively treated $(p<0.001)$. There was a tendency to more in-hospital complications in the operative group $(p=0.059)$. The rate of surgery-related complications (8.3\%) was low with only one revision needed. Selected outcome parameters improved during the observation period nearly reaching the level before FFP after 1 year. SF-8 PCS, Barthel index and rate of patients living home were higher in the operative group at $\mathrm{t} 4$. The improvement of autonomy (independent walking) between $\mathrm{t} 1$ and $\mathrm{t} 4$ was significant in the operated group $(p=0.04)$ but not in the conservative group $(p=0.96)$. One-year mortality rate was $11.7 \%$ with no difference between the fracture types. One-year mortality rate of conservatively treated patients with FFP type II-IV was $13.5 \%$ versus $6.9 \%$ in the operative group $(p=0.38)$.

Conclusion Conservative treatment is appropriate in patients with FFP type I as well as in patients with FFP type II, provided that the last ones are hospitalized immediately after the traumatic event. Surgical treatment is recommended in patients with higher fracture types, with delayed presentation or after unsuccessful conservative treatment. In the conservative and operative group, all selected parameters considerably improved between $\mathrm{t} 1$ and $\mathrm{t} 4 \mathrm{with}$ a steeper increase in the operative group. The rate of postoperative complications is low. The 1-year mortality rate is the lowest in the operative group. Surgical stabilization of FFP is safe and reliable provided it is performed with care and in the appropriate target group.
\end{abstract}

Keywords Pelvis $\cdot$ Fragility fracture $\cdot$ Prospective $\cdot$ Conservative $\cdot$ Operative $\cdot$ Outcome $\cdot$ Delayed hospitalization $\cdot$ Mortality $\cdot$ Complications

Extended author information available on the last page of the article 


\section{Introduction}

There is a growing clinical-scientific interest in fragility fractures of the pelvis (FFP) [1]. The incidence of this emerging pathology is increasing due to higher life expectancy and high rates of osteoporosis in elderly women [2,3]. The characteristics of FFP are not comparable to those of pelvic fractures in younger patients. Not only are trauma mechanisms completely different, also clinical symptoms, fracture patterns and natural course are unique and diverse [4, 5]. Clinical data on the origin, diagnosis, treatment strategy and outcome of FFP become increasingly available, but there still is uncertainty and controversy on how to manage these lesions [6-8]. Several authors bring arguments for conservative, others for operative treatment [9-11]. Osterhoff et al. state that patients with FFP are of old age and present with several comorbidities. Conservative treatment is the least invasive. Adequate pain therapy enables quick mobilisation and early discharge from hospital. Operatively treated patients stay longer in the hospital. A long hospital-stay enhances the risk of general complications such as urinary tract infection, pneumonia or bedsores. Surgical treatment is more invasive and may be connected with complications such as hematoma, infection, malposition or loosening of implants [9, 10]. On the contrary, Wagner et al. described lower mortality and better mobility after surgical stabilization [11]. Nevertheless, Rommens et al. found out that open surgical procedures are responsible for more complications than less-invasive stabilisation techniques [10].

The FFP-classification provides a frame for analysis of these lesions. It is based on the analysis of conventional radiographs and pelvic CT-data of 245 patients with FFP. The classification distinguishes between four different levels of instability. Patients with FFP type I have isolated anterior pelvic ring fractures. Patients with FFP type II have non-displaced posterior pelvic ring lesions. Patients with FFP type III have unilaterally displaced posterior ring lesions and patients with FFP type IV have bilaterally displaced posterior ring lesions [12]. The intra-rater and inter-rater reliabilities of the FFP-classification have been validated in a multicentre study [13]. In the original publication, the FFP-classification was connected with recommendations for surgical treatment. So far, they were not validated by prospective studies. Published studies merely focus on indications, timing and techniques of surgical stabilization $[8,9,14,15]$. This prospective study investigates which factors influence decision making and outcome of patients with FFP.

\section{Materials and methods}

We prospectively collected demographics and medical history of all patients, who were admitted at our department between mid-2018 and mid-2020 (2-year period) with the diagnosis of fragility fractures of the pelvis (FFP). FFP were diagnosed by means of anamnesis, conventional pelvic radiographs (a.-p., inlet and outlet) and pelvic computer tomography (CT) and classified by the first and last author in accordance to the FFP-classification [12]. The quality of life $(\mathrm{QoL})$ before the fracture was retrospectively collected with the Short Form-8 Physical and Mental Component Scores (SF-8 PCS and SF-8 MCS) [16] and with the European Quality of Life-5 Dimensions-5 Levels (EQ-5D-5L) questionnaire $[17,18]$ at hospital admission. The following data are additionally collected at admission (timepoint $1=\mathrm{t} 1$ ): age, sex, trauma mechanism, start of complaints in case no trauma was memorable, comorbidities, EQ-5D-5L, level of autonomy (independent walking, walking with sticks, walking with walking frame or rollator, bedridden), most recent living environment, Barthel index [19], Parker Mobility Score (PMS) [20] and Numeric Rating Scale on load (NRS) [21]. A comorbidity was defined as a known disease with which the patient is admitted. In accordance with the recommendations of Rommens and Hofmann [12, 22], conservative treatment was given for patients with FFP type I and FFP type II. Surgical stabilization was recommended for patients with FFP type III and FFP type IV. Surgical stabilization was also recommended after 5-7 days for patients with FFP type II in case of unsuccessful conservative treatment (Fig. 1a-f).

At discharge (timepoint $2=\mathrm{t} 2$ ), the following data are collected: type of management (conservative versus operative), type of surgical stabilization, length of hospital stay ( $\mathrm{LoS}$ ), general in-hospital complications, surgery-related complications, in-hospital mortality, level of autonomy and destination. Additionally, the following scores were collected: SF-8 PCS, SF-8 MCS, EQ-5D-5L, Barthel index, PMS and NRS.

Patients or their relatives were contacted by phone 3 months (timepoint $3=\mathrm{t} 3$ ) and 12 months (timepoint $4=\mathrm{t} 4$ ) after primary admission. Their general practitioner or the bureau of vital statistics was contacted to ask about their vital status, if patients were not directly available. The following data were collected at $\mathrm{t} 3$ and $\mathrm{t} 4$ : actual living environment, level of autonomy, mortality, SF-8 PCS and SF-8 MCS, EQ-5D-5L, Barthel index, PMS and NRS. The number of new fragility fractures and new hospitalizations within the first year were also noticed.

All included patients or their relatives gave their written approval for participation in the study, data collection and analysis. Personal data were anonymized before analysis. The study was approved by the local ethics committee (Reference: 837.140.17 (10974)).

We tested continuous data for normal distribution using the Kolmogorov Smirnov test. Descriptive statistics in normally distributed data were described as mean and standard deviation. In non-normally distributed data, median and the 25 th and 75 th interquartile ranges (IQR) were calculated. 

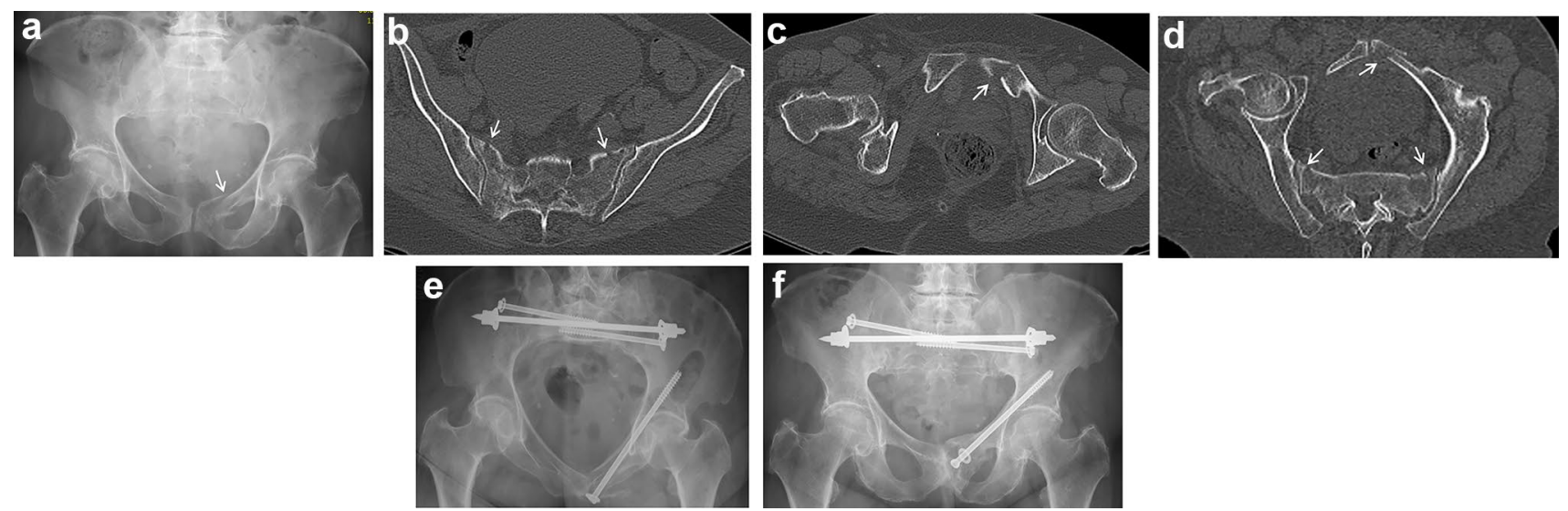

Fig. 1 a-f A 77-year-old woman suffered severe pelvic pain after a fall at home. The a.p. pelvic overview shows a left superior and inferior pubic ramus fracture (arrow) (a). A transverse CT-cut through the sacrum shows bilateral non-displaced sacral alar fractures, complete on the right and incomplete on the left side (arrows) (b). Transverse CT-cut through the pubic symphysis confirms the left-sided superior pubic ramus fracture (arrow) (c). Oblique CT-cut though the level of the pelvic brim shows the posterior and anterior instabilities of the pelvic ring (arrows) (d). These fractures corresponded with a

Different groups were compared using the non-paired student's $t$ test (normally distributed data) and the Mann-Whitney- $U$ test (non-normally distributed data). Nominal groups were compared using the chi-square test. A $p$ value of $\leq 0.05$ was considered to be significant. Statistical analysis was performed using SPSS software (IBM SPSS Statistics for Windows, Version 23; IBM Corp, Armonk, NY, USA).

\section{Results}

\section{All patients}

110 were included in the study (t1). At $\mathrm{t} 2$, there were 108 patients left with complete documentation, at $\mathrm{t} 388$ and at t4 75 patients. The reasons for exclusion during the course of the study are depicted in the Fig. 2. The mean age of all 110 patients was 79.2 years (SD 10 years). There were 99 women $(90 \%)$ and 11 men (10\%). Before hospital admission, 94 patients $(85.5 \%)$ lived independently or with assistance in their own home. Fourteen patients had FFP type I (12.7\%), 59 FFP type II (53.6\%), 11 FFP type III (10\%) and 26 FFP type IV fractures (23.6\%). 99 patients (90\%) presented with comorbidities. 63 patients had a history of osteoporosis (57.3\%), 40 already suffered another fragility fracture before suffering FFP (36.4\%) and only 38 received and antiresorptive medication (34.5\%). Only $20 \%$ of patients could walk independently at $\mathrm{t} 1.62$ patients were treated conservatively $(56.4 \%)$ and 48 operatively (43.6\%). The frequency and type of surgical techniques for stabilization of
FFP type IIc. The patient was treated conservatively during 1 week. Due to continuing immobilizing pain, surgical stabilization was performed after 8 days. The fractures were fixed operatively with a transsacral bar and bilateral iliosacral screws. The pubic ramus fracture was stabilized with a retrograde transpubic screw. Postoperative pelvic inlet view (e). The a.p. pelvic overview more than one year after surgery shows complete healing of all fractures. There is a slight loosening of the retrograde transpubic screw (f)

the posterior and anterior pelvis, depending on the FFP-classification, are shown in Table 1. With the exception of plate and screw osteosynthesis for fractures of the posterior pelvis $(n=3)$ and the anterior pelvis $(n=9)$, all procedures were performed minimally invasive. Median LoS was 11 days (min 3-max 42 days, IQR 8-17 days). There were general in-hospital complications in 29 patients (26.9\%). There were surgery-related complications in 4 patients $(4 / 48=8.3 \%)$ and only one surgical revision was needed $(1 / 48=2.1 \%)$. There was no in-hospital mortality. The one-year mortality rate was $11.7 \%$ for the whole group. Between $\mathrm{t} 2$ and $\mathrm{t} 4,11$ patients suffered an additional osteoporotic fracture (14.7\%) and 27 patients were re-hospitalized for any reason (36.0\%). Demographics and selected parameters of all patients during hospitalization and during the course of the observation period are depicted in Table 2 . The evolution of the patientreported outcomes is depicted in Table 3.

\section{FFP type I}

There were only 14 patients with FFP type I (isolated anterior pelvic fracture). Their mean age was 81.3 years (SD 9.6 years). There were 11 women (78.6\%) and 3 men $(21.4 \%)$. Twelve patients $(85.7 \%)$ lived independently or with assistance in their own home. All patients presented with comorbidities. All patients were treated conservatively. Median hospital stay was 9 days (min 4-max 41 days, IQR 7-15 days). There were general in-hospital complications in 5 patients (38.5\%). Between $\mathrm{t} 2$ and $\mathrm{t} 4,2$ patients suffered a fracture progression and needed a surgical stabilization. 
Fig. 2 Flowchart of included and excluded patients during the course of the study

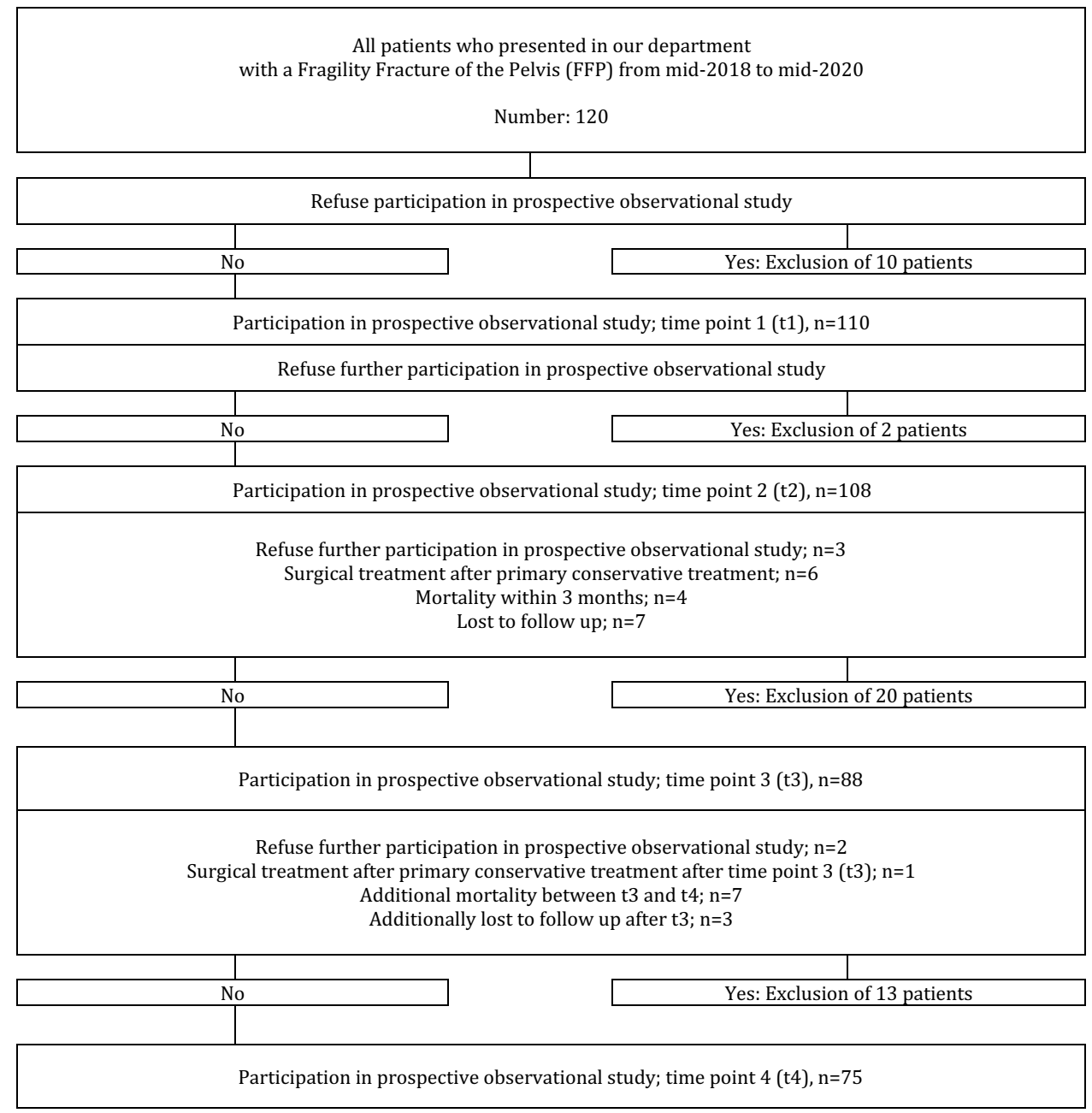

Two additional patients suffered another osteoporotic fracture and needed re-hospitalization. At $\mathrm{t} 4$, four of the remaining patients lived at home $(57.1 \%)$ but only one could walk without aid (14.3\%). One-year mortality rate was $11.1 \%$. Demographics and selected parameters of patients with FFP type I during hospitalization and during the course of the observation period are depicted in Table 2 . The evolution of the patient-reported outcomes is depicted in Table 4.

\section{FFP types II-IV}

96 patients had FFP with involvement of the posterior pelvic ring (FFP type II, FFP type III or FFP type IV) $(87.3 \%$ ). Their mean age was 78.9 years (SD 10.0 years). There were 88 women $(91.7 \%)$ and 8 men $(8.3 \%) .74$ patients $(77.1 \%)$ lived independently or with assistance in their own home. 85 patients presented with comorbidities (88.5\%). 48 patients were treated conservatively $(50.0 \%)$ and 48 operatively (50.0\%). Demographics and selected parameters of patients with FFP type II-IV during hospitalization and during the course of the observation period are depicted in
Table 2. The evolution of the patient-reported outcomes is depicted in Table 5. There were several important differences between the conservative and operative group. Conservatively treated patients were hospitalized at the day of trauma, whereas operatively treated patients were admitted at a median of 33.5 days after beginning of complaints $(p<0.001)$. The clinical condition of the patients, who were treated operatively later on, was worse at admission: only $12.5 \%$ of the operative group could walk independently but $27.1 \%$ of the conservative group. Moreover, SF-8 PCS and EQ-5D-5L were lower in the operative group before trauma and at the time of hospitalization. Surgery was performed at a median of 6 days after admission and operatively treated patients stayed 6 days longer in hospital (15 versus 9 days) $(p<0.001)$. There was a tendency to more general in-hospital complications in the operative group $(34.0 \%$ versus $16.7 \%)(p=0.059)$, mainly because of urinary tract infection $(p=0.011)$. Surgery-related complications were seen in 4 patients $(8.3 \%)$. Five patients of the conservative group (10.4\%) needed a secondary operative stabilization because of fracture progression or unsuccessful conservative 
Table 1 Frequency and type of surgical techniques for stabilization of the posterior and anterior pelvis, depending on FFP-classification, surgery-related complications and revisions, secondary operative treatment

\begin{tabular}{|c|c|c|c|c|c|}
\hline FFP-categories & FFP types I-IV & FFP type I & FFP type II & FFP type III & FFP type IV \\
\hline Number of operatively treated patients & 48 & 0 & 14 & 10 & 24 \\
\hline \multicolumn{6}{|l|}{ Posterior Pelvis } \\
\hline Transsacral bar with bilateral iliosacral screws & 16 & 0 & 4 & 0 & 12 \\
\hline Transiliac internal fixator with bilateral iliosacral screws & 10 & 0 & 2 & 0 & 8 \\
\hline Transiliac internal fixator with unilateral iliosacral screw & 7 & 0 & 3 & 3 & 1 \\
\hline Transsacral bar with unilateral iliosacral screw & 3 & 0 & 1 & 1 & 1 \\
\hline Plate and screw osteosynthesis ilium & 3 & 0 & 0 & 3 & 0 \\
\hline Transiliac internal fixator with bilateral transsacral screws & 3 & 0 & 1 & 1 & 1 \\
\hline Iliosacral screw unilateral & 2 & 0 & 1 & 1 & 0 \\
\hline Iliosacral screws bilateral & 1 & 0 & 1 & 0 & 0 \\
\hline Screw osteosynthesis ilium unilateral & 1 & 0 & 0 & 1 & 0 \\
\hline Transsacral bar & 1 & 0 & 1 & 0 & 0 \\
\hline Bilateral transsacral screws with bilateral iliosacral screws & 1 & 0 & 0 & 0 & 1 \\
\hline \multicolumn{6}{|l|}{ Anterior Pelvis } \\
\hline Unilateral retrograde transpubic screw & 17 & 0 & 3 & 6 & 8 \\
\hline Plate and screw osteosynthesis & 9 & 0 & 1 & 1 & 7 \\
\hline Bilateral retrograde transpubic screw & 4 & 0 & 3 & 1 & 0 \\
\hline Retrograde transpubic screw and plate and screw osteosynthesis & 1 & 0 & 0 & 1 & 0 \\
\hline Surgery-related complications - total & 4 & n.a. & 2 & 0 & 2 \\
\hline Malposition & 2 & & 2 & 0 & 0 \\
\hline Malposition and paresis & 1 & & 0 & 0 & 1 \\
\hline Plate breakage & 1 & & 0 & 0 & 1 \\
\hline Surgical revisions & 1 & n.a. & 0 & 0 & 1 \\
\hline $\begin{array}{l}\text { Secondary operative treatment (after primary conservative treatment) } \\
*\end{array}$ & $7 / 62$ & $2 / 14$ & $4 / 45$ & $1 / 1$ & $0 / 2$ \\
\hline
\end{tabular}

*The figures show the number of secondarily operated patients in relation to the total number of primarily conservatively treated patients n.a. not applicable

treatment. One-year mortality rate was $11.8 \%$ for all patients with FFP types II-IV, $13.5 \%$ for the conservative and $6.9 \%$ for the operative group $(p=0.38)$. After 1 year $(\mathrm{t} 4), 92.3 \%$ of the operative and $86.2 \%$ of the conservative group lived at home. $30.8 \%$ of the operative versus $27.6 \%$ of the conservative group regained full autonomy (independent walking). The rate of patients living at home, the SF- 8 PCS and Barthel index was higher in the operative group. The improvement of autonomy between $\mathrm{t} 1$ and $\mathrm{t} 4$ was significant in the operated group $(p=0.04)$ but not in the conservative group $(p=0.96)$.

\section{FFP type II conservative and operative}

59 patients suffered FFP type II. Mean age was 80.2 years (SD 9.6 years). There were 51 women $(86.4 \%)$ and 8 men (13.6\%). 51 patients lived independently or with assistance in their own home $(86.5 \%) .45$ were treated conservatively $(76.3 \%), 14$ operatively $(23.7 \%)$. Demographics and selected parameters of patients with FFP type II during hospitalization and during the course of the observation period are depicted in Table 6 . The evolution of the patient-reported outcomes is depicted in Table 7. There were some important differences between the conservative and operative group. Operatively treated patients were 3 years younger than the conservatively treated (77.9 versus 80.9 years $)(p=0.19)$, had more often osteoporosis in their medical history $(78.6 \%$ versus $51.1 \%)(p=0.07)$ and presented much later after the onset of complaints (15.5 days versus 0 days $)(p=0.002)$. Before trauma and at t1, SF-8 PCS and EQ-5D-5L were lower in the operative group and autonomy of the operatively treated patients was more severely restricted than of the conservatively treated $(7.1 \%$ walked without aid versus $28.9 \%$ ). Operative patients were operated at a median of 8 days after admission. Median LoS of the operative group was 17 days versus 9 days in the conservative group $(p<0.001)$. There were slightly more general in-hospital complications in the operative group $(23.1 \%)$ than in the conservative group $(17.8 \%)$ but without significant difference $(p=0.69)$. There 
Table 2 Demographics, type of treatment and selected data of all patients, of patients with FFP I and of conservatively and operatively treated patients with FFP type II-V during the course of the observation period

\begin{tabular}{|c|c|c|c|c|c|}
\hline & All patients & FFP type I & $\begin{array}{l}\text { FFP type II-IV } \\
\text { conservative }\end{array}$ & $\begin{array}{l}\text { FFP type II-IV } \\
\text { operative }\end{array}$ & $p$ value \\
\hline Patients; $n(\%)$ & $110(100.0)$ & $14(12.7)$ & $48(43.6)$ & $48(43.6)$ & \\
\hline Mean age (years) & 79.2 & 81.3 & 80.9 & 76.8 & 0.04 \\
\hline Standard Deviation (SD) (years) & 10.0 & 9.6 & 9.7 & 9.9 & \\
\hline Women; $n(\%)$ & $99(90.0)$ & $11(78.6)$ & $41(85.4)$ & $47(97.9)$ & 0.059 \\
\hline Men; $n(\%)$ & $11(10.0)$ & $3(21.4)$ & $7(14.6)$ & $1(2.1)$ & 0.059 \\
\hline Patients with comorbidities; $n(\%)$ & $99(90.0)$ & $14(100.0)$ & $43(89.6)$ & $42(87.5)$ & 0.75 \\
\hline Patients with two or more comorbidities; $n(\%)$ & $63(57.3)$ & $10(71.4)$ & $28(58.3)$ & $25(52.1)$ & 0.54 \\
\hline Osteoporosis in medical history; $n(\%)$ & $63(57.3)$ & $7(50.0)$ & $25(52.1)$ & $31(64.6)$ & 0.21 \\
\hline Previous osteoporotic fracture; $n(\%)$ & $40(36.4)$ & $5(35.7)$ & $15(31.3)$ & $20(41.7)$ & 0.29 \\
\hline Patients with more than 5 different drugs per day; $n(\%)$ & $75(68.2)$ & $9(64.3)$ & $34(70.8)$ & $32(66.7)$ & 0.66 \\
\hline Anti-resorptive medication; $n(\%)$ & $38(34.5)$ & $5(35.7)$ & $15(31.3)$ & $18(37.5)$ & 0.52 \\
\hline \multicolumn{6}{|l|}{ Living situation before admission; $n(\%)$} \\
\hline Independently at home & $83(75.5)$ & $9(64.3)$ & $36(75,0)$ & $38(79.2)$ & 0.63 \\
\hline Assisted living at home & $11(10.0)$ & $3(21.4)$ & $4(8.3)$ & $4(8.3)$ & 1 \\
\hline Nursing home & $9(8.2)$ & $0(0.0)$ & $6(12.5)$ & $3(6.3)$ & 0.49 \\
\hline Hospital & $7(6.4)$ & $2(14.3)$ & $2(4.2)$ & $3(6.3)$ & 1 \\
\hline \multicolumn{6}{|l|}{ Trauma mechanism; $n(\%)$} \\
\hline Fall from standing position & $74(67.3)$ & $13(92.9)$ & $36(75.0)$ & $25(52.2)$ & 0.01 \\
\hline Recurrent falls & $8(7.3)$ & $1(7.1)$ & $3(6.3)$ & $4(8.3)$ & 1 \\
\hline No trauma memorable & $28(25.5)$ & $0(0.0)$ & $9(18.8)$ & $19(39.6)$ & 0.02 \\
\hline \multicolumn{6}{|c|}{ Time between trauma or beginning of complaints and t1 (days) } \\
\hline Median & 4 & 0 & 0 & 33.5 & $<0.001$ \\
\hline Min & 0 & 0 & 0 & 0 & \\
\hline Max & 361 & 61 & 123 & 361 & \\
\hline \multicolumn{6}{|l|}{ Type of primary treatment; $n(\%)$} \\
\hline Conservative & $62(56.4)$ & $14(100.0)$ & $48(100.0)$ & $0(0.0)$ & 1 \\
\hline Operative & $48(43.6)$ & $0(0.0)$ & $0(0.0)$ & $48(100.0)$ & 1 \\
\hline Median length of hospital stay (days) & 11 & 9 & 9 & 15 & $<0.001$ \\
\hline Median length of postoperative hospital stay (days) & n.a. & n.a. & n.a. & 9 & \\
\hline Patients with general in-hospital complications, $n(\%)$ & $29(26.9)$ & $5(38.5)$ & $8(16.7)$ & $16(34.0)$ & 0.059 \\
\hline Urinary tract infection; $n$ & 19 & 2 & 3 & 13 & 0.011 \\
\hline Pneumonia; $n$ & 9 & 1 & 4 & 4 & 1 \\
\hline Bedsore; $n$ & 3 & 0 & 1 & 3 & 0.62 \\
\hline Patients with surgery-related complications; $n(\%)$ & n.a. & n.a. & n.a. & $3(6.3)$ & \\
\hline Implant malposition; $n$ & & & & 3 & \\
\hline Paresis; $n$ & & & & 1 & \\
\hline Surgical revisions; $n(\%)$ & n.a. & n.a. & n.a. & $1(2.1)$ & \\
\hline Secondary operative treatment; $n(\%)$ & $7(6.4)$ & $2(14.3)$ & $5(10.4)$ & n.a & \\
\hline One-year mortality rate; $\%$ & 11.7 & 11.1 & 13.5 & 6.9 & 0.38 \\
\hline New osteoporotic fracture between $\mathrm{t} 2$ and $\mathrm{t} 4 ; n(\%)$ & $11(14.7)$ & 2/7 (28.6) & $2(4.8)$ & $7(15.9)$ & 0.157 \\
\hline Re-hospitalization rate between $\mathrm{t} 2$ and $\mathrm{t} 4 ; n(\%)$ & $27(36.0)$ & $2 / 7(28.6)$ & $17(48.7)$ & $15(33.6)$ & 0.393 \\
\hline
\end{tabular}

n.a. not available; $p$ values $<0.05$ are depicted in bold

were surgery-related complications in 2 patients (15.4\%) but no surgical revisions needed. Four patients of the conservative group (8.9\%) underwent secondary operative treatment because of fracture progression. One-year mortality rate was $14.5 \%$ in the conservative and $7.3 \%$ in the operative group $(p=0.548)$. At $t 4,85.2 \%$ of the conservative group and $81.8 \%$ of the operative group lived at home. $29.6 \%$ of the conservative and $27.3 \%$ of the 
Table 3 Patient-reported outcomes of all patients $(n=110)$ during the course of the observation period

\begin{tabular}{llllll}
\hline & Before trauma & $\mathrm{t} 1$ & $\mathrm{t} 2$ & $\mathrm{t} 3$ & $\mathrm{t} 4$ \\
\hline Patients living at home independently or with assistance (\%) & 85.5 & n.a. & 39.8 & 79.5 & 86.7 \\
Short Form-8 Physical Component Score (median) & 40.67 & n.a. & 23.92 & 32.78 & 36.77 \\
Short Form-8 Mental Component Score (median) & 57.25 & n.a. & 55.32 & 56.93 & 55.65 \\
European Quality of Life-5 Dimensions-5 Levels (median) & 0.86 & 0.16 & 0.34 & 0.76 & 0.72 \\
Patients walking independently (\%) & n.a. & 20 & 4.6 & 23.8 & 28.0 \\
Barthel index (median) & n.a. & 45 & 65 & 85 & 90 \\
Parker mobility score (median) & n.a. & 1 & 2 & 4 & 5 \\
Numeric rating scale on load (median) & n.a. & 10 & 7 & 4 & 4 \\
\hline
\end{tabular}

n.a. not available

\begin{tabular}{llllll}
\hline & Before trauma & $\mathrm{t} 1$ & $\mathrm{t} 2$ & $\mathrm{t} 3$ & $\mathrm{t} 4$ \\
\hline Patients living at home independently or with assistance (\%) & 85.7 & n.a. & 30.8 & 37.5 & 57.1 \\
Short Form-8 Physical Component Score (median) & 47.62 & n.a. & 23.11 & 35.02 & 31.5 \\
Short Form-8 Mental Component Score (median) & 56.82 & n.a. & 61.94 & 51.09 & 55.53 \\
European Quality of Life-5 Dimensions-5 Levels (median) & 0.92 & 0.14 & 0.24 & 0.56 & 0.8 \\
Patients walking independently (\%) & n.a. & 21.4 & 0.0 & 12.5 & 14.3 \\
Barthel index (median) & n.a. & 30 & 55 & 75 & 85 \\
Parker Mobility Score (median) & n.a. & 0 & 1 & 5 & 5 \\
Numeric Rating Scale on load (median) & n.a. & 10 & 7 & 4 & 4 \\
\hline
\end{tabular}

n.a. not available
Table 4 Patient-reported outcomes of patients with FFP type I $(n=14)$ during the course of the observation period operative group could walk independently. Whereas the rate of patients with full autonomy (independent walking) did not change between $\mathrm{t} 1$ and $\mathrm{t} 4(28.9 \%$ at $\mathrm{t} 1$ and $29.6 \%$ at 4 ) in the conservative group, this rate changed importantly in the operative group (7.1\% at $\mathrm{t} 1$ and $27.3 \%$ at $\mathrm{t} 4$ ).

\section{FFP type III}

Eleven female patients suffered FFP type III. Mean age was 78.1 years (SD 12.4 years). Nine patients lived independently or with assistance in their own home (81.8\%). Only one patient was primarily treated conservatively $(9.1 \%)$ but needed secondary surgery due to fracture progression. Ten patients were primarily treated operatively (90.9\%). Demographics and selected parameters of patients with FFP type III during hospitalization and during the course of the observation period are depicted in Table 8. The evolution of the patient-reported outcomes is depicted in Table 9. The patients presented at an average of 6.5 days after the onset of complaints and were operated at a median of 5 days after admission. The LoS was 14 days. There were general in-hospital complications in 4 patients (40\%), mainly due to urinary tract infection, but there was no surgery-related complication. The 1-year mortality rate was $6.7 \%$. At $t 4$, all remaining patients lived at home (100\%). Whereas at $44, \mathrm{EQ}-5 \mathrm{D}-5 \mathrm{~L}$ was lower than in patients with FFP type II, SF-8 PCS, SF-8 MCS and Barthel index were comparable.

\section{FFP type IV}

Twenty-six female patients suffered FFP type IV. Mean age was 76.1 years (SD 8.9 years). 22 patients lived independently or with assistance in their own home (84.6\%). Two patients were treated conservatively $(7.7 \%)$ and 24 patients operatively (92.3\%) (Fig. 3a-f). All patients presented with comorbidities, 16 had osteoporosis in their medical history (66.7\%). Demographics and selected parameters of patients with FFP type IV during hospitalization and during the course of the observation period are depicted in Table 8. The evolution of the patient-reported outcomes is depicted in Table 9. Patients with FFP type IV presented at a median of 41 days after the onset of complaints. Patients were operated at a median of 5 days after admission, and their median LoS was 14 days. There were general inhospital complications in nine patients (34.6\%), mainly because of urinary tract infection. A surgery-related complication was present twice $(8.3 \%)$. One patient needed removal of an iliosacral screw because of malposition and paresis $(4.2 \%)$. One-year mortality rate was $9.1 \%$. At $t 4$, $95 \%$ of the operated patients lived at home. Whereas only $16.7 \%$ walked independently at $\mathrm{t} 1(16.7 \%), 30.0 \%$ walked independently at $\mathrm{t} 4$. There was a steady improvement in all 
Table 5 Patient-reported outcomes of conservatively $(n=48)$ and operatively $(n=48)$ treated patients with FFP types II-IV during the course of the observation period

\begin{tabular}{|c|c|c|c|c|c|}
\hline & Before trauma & $\mathrm{t} 1$ & $\mathrm{t} 2$ & $\mathrm{t} 3$ & $\mathrm{t} 4$ \\
\hline \multicolumn{6}{|c|}{ Patients living at home independently or with assistance (\%) } \\
\hline $\begin{array}{l}\text { FFP types II-IV con- } \\
\text { servative }\end{array}$ & 83.3 & n.a. & 37.5 & 79.4 & 86.2 \\
\hline $\begin{array}{l}\text { FFP types II-IV opera- } \\
\text { tive }\end{array}$ & 87.5 & n.a. & 44.7 & 86.7 & 92.3 \\
\hline \multicolumn{6}{|c|}{ Short Form-8 Physical Component Score (median) } \\
\hline $\begin{array}{l}\text { FFP types II-IV con- } \\
\text { servative }\end{array}$ & 41.09 & n.a. & 23.71 & 34.95 & 34.8 \\
\hline $\begin{array}{l}\text { FFP types II-IV opera- } \\
\text { tive }\end{array}$ & 35.77 & n.a. & 23.91 & 31.23 & 39.63 \\
\hline \multicolumn{6}{|c|}{ Short Form-8 Mental Component Score (median) } \\
\hline $\begin{array}{l}\text { FFP types II-IV con- } \\
\text { servative }\end{array}$ & 57.25 & n.a. & 52.52 & 57.48 & 56.68 \\
\hline $\begin{array}{l}\text { FFP types II-IV opera- } \\
\text { tive }\end{array}$ & 55.83 & n.a. & 55.43 & 55.46 & 55.61 \\
\hline \multicolumn{6}{|c|}{ European Quality of Life - 5 Dimensions - 5 Levels (median) } \\
\hline $\begin{array}{l}\text { FFP types II-IV con- } \\
\text { servative }\end{array}$ & 0.9 & 0.17 & 0.35 & 0.76 & 0.7 \\
\hline $\begin{array}{l}\text { FFP types II-IV opera- } \\
\text { tive }\end{array}$ & 0.85 & 0.14 & 0.33 & 0.76 & 0.7 \\
\hline \multicolumn{6}{|c|}{ Patients walking independently (\%) } \\
\hline $\begin{array}{l}\text { FFP types II-IV con- } \\
\text { servative }\end{array}$ & n.a. & 27.1 & 4.2 & 35.3 & 27.6 \\
\hline $\begin{array}{l}\text { FFP types II-IV opera- } \\
\text { tive }\end{array}$ & n.a. & 12.5 & 6.4 & 15.6 & 30.8 \\
\hline \multicolumn{6}{|l|}{ Barthel index (median) } \\
\hline $\begin{array}{l}\text { FFP types II-IV con- } \\
\text { servative }\end{array}$ & n.a. & 45 & 60 & 85 & 87.5 \\
\hline $\begin{array}{l}\text { FFP types II-IV opera- } \\
\text { tive }\end{array}$ & n.a. & 45 & 75 & 85 & 95 \\
\hline \multicolumn{6}{|c|}{ Parker Mobility Score (median) } \\
\hline $\begin{array}{l}\text { FFP types II-IV con- } \\
\text { servative }\end{array}$ & n.a. & 1 & 2 & 4 & 5 \\
\hline $\begin{array}{l}\text { FFP types II-IV opera- } \\
\text { tive }\end{array}$ & n.a. & 1 & 2 & 4 & 6 \\
\hline \multicolumn{6}{|c|}{ Numeric Rating Scale on load (median) } \\
\hline $\begin{array}{l}\text { FFP types II-IV con- } \\
\text { servative }\end{array}$ & n.a. & 10 & 8 & 3 & 2 \\
\hline $\begin{array}{l}\text { FFP types II-IV opera- } \\
\text { tive }\end{array}$ & n.a. & 9 & 5 & 5 & 5 \\
\hline
\end{tabular}

n.a. not available

patient-reported outcomes between $\mathrm{t} 1$ and $\mathrm{t} 4$. The ultimate values were comparable with operatively treated patients with FFP type II and type III. Nevertheless, there was a higher sensation of pain on load.

\section{Discussion}

In this prospective study, we searched for key factors, which influence treatment strategy and outcome in patients with FFP. We could include 110 patients in a 2-year period.

Characteristics of included patients were similar to the data of other studies: FFP-patients are of old age, the large majority being females [7-9, 14, 23] and presenting with comorbidities. More than half of our patients suffered from osteoporosis and more than one-third suffered another osteoporotic fracture before FFP although only one third (34.5\%) had an antiresorptive medication at first presentation. Most patients lived independently or with assistance in their own environment. All patients with FFP type I as well as 76.3\% of the patients with FFP type II were primarily treated conservatively. $91.9 \%$ of patients with FFP type III-IV were treated operatively. The mean age of operated patients was 4.1 years younger than of conservative patients $(p=0.04)$. We find comparable data in the series of Oberkircher et al. [15], Gericke et al. [24] and Höch et al. [25]. Lower age may have played a role in favor of surgical treatment in these trauma centers.

The most important finding in our study is that those patients, who ultimately received an operative treatment, had more unstable FFP types, were hospitalized later after the onset of their complaints and presented in a worse clinical form due to FFP. These conditions can be regarded as key factors in favor of operative treatment. Patients, who received surgical treatment, were admitted at a median of 1 month (33.5 days) after the onset of complaints whereas the median day of admission of the conservative group was the day of trauma $(p<0.001)$. In FFP type II, there was a difference of 15.5 days, in FFP type III of 6.5 days and in FFP type IV of 41 days. These patients received a conservative outpatient treatment by family doctors or orthopedists and were later hospitalized. At $\mathrm{t} 1$, the loss of autonomy of the operated group was importantly larger than that of the conservative group: only $12.5 \%$ of the operated group could walk without aid versus $27.1 \%$ of the conservative group. One year later, at $\mathrm{t} 4$, we see that autonomy in the conservative group did not ameliorate whereas autonomy of the operated patients was significantly better. From these data, we can conclude that patients, who present late after FFP and are hospitalized in a reduced clinical condition benefit from surgical treatment.

Especially in FFP type II patients, there is an ongoing debate on when operative treatment is beneficial. In our series, the operative FFP type II group had less autonomy (independent walking) and lower EQ-5D-5L, SF-8 PCS and Barthel index scores before and at hospital admission than the conservative group. The surgical procedure was merely performed at a median of 8 days after admission with the 
Table 6 Demographics, type of treatment and selected data of conservatively and operatively treated patients with FFP type II during the course of the observation period

\begin{tabular}{|c|c|c|c|c|}
\hline & $\begin{array}{l}\text { All patients with } \\
\text { FFP type II }\end{array}$ & $\begin{array}{l}\text { FFP type II conserva- } \\
\text { tive treatment }\end{array}$ & $\begin{array}{l}\text { FFP type II operative } \\
\text { treatment }\end{array}$ & $p$ value \\
\hline Number $(\%)$ & $59(100)$ & $45(76.3)$ & $14(23.7)$ & \\
\hline Mean age (years) & 80.2 & 80.9 & 77.9 & 0.19 \\
\hline Standard Deviation (SD) & 9.6 & 9.7 & 9.1 & \\
\hline Women; $n(\%)$ & $51(86.4)$ & $38(84.4)$ & $13(92.9)$ & 0.67 \\
\hline Men; $n(\%)$ & $8(13.6)$ & $7(15.6)$ & $1(7.1)$ & 0.67 \\
\hline Patients with comorbidities; $n(\%)$ & $53(89.8)$ & $40(88.9)$ & $13(92.9)$ & 1 \\
\hline Patients with two comorbidities or more; $n(\%)$ & $32(54.2)$ & $26(57.8)$ & $6(42.9)$ & 0.33 \\
\hline Osteoporosis in medical history; $n(\%)$ & $34(57.6)$ & $23(51.1)$ & $11(78.6)$ & 0.07 \\
\hline Previous osteoporotic fracture, $n(\%)$ & $21(35.6)$ & $14(31.1)$ & $7(50.0)$ & 0.22 \\
\hline Patients with more than 5 different drugs per day; $n(\%)$ & $41(69.5)$ & $32(71.1)$ & $9(64.3)$ & 0.74 \\
\hline Anti-resorptive medication; $n(\%)$ & $19(32.2)$ & $14(31.1)$ & $5(35.7)$ & 0.75 \\
\hline \multicolumn{5}{|l|}{ Living situation before admission; $n(\%)$} \\
\hline Independently & $44(74.6)$ & $35(77.8)$ & $9(64.3)$ & 0.31 \\
\hline Assisted living & $7(11.9)$ & $4(8.9)$ & $3(21.4)$ & 0.34 \\
\hline Nursing home & $5(8.5)$ & $4(8.9)$ & $1(7.1)$ & 1 \\
\hline Hospital & $3(5.1)$ & $2(4.4)$ & $1(7.1)$ & 0.56 \\
\hline \multicolumn{5}{|l|}{ Trauma mechanism; $n(\%)$} \\
\hline Fall from standing position & $42(71.2)$ & $34(75.6)$ & $8(57.1)$ & 0.14 \\
\hline Recurrent falls & $3(5.1)$ & $3(6.7)$ & $0(0.0)$ & 0.14 \\
\hline No trauma memorable & $14(23.7)$ & $8(17.8)$ & $6(42.9)$ & 0.14 \\
\hline \multicolumn{5}{|c|}{ Time between trauma or beginning of complaints and $\mathbf{t} 1$ (days) } \\
\hline Median & 1 & 0 & 15.5 & 0.002 \\
\hline Min & 0 & 0 & 0 & \\
\hline Max & 123 & 123 & 121 & \\
\hline Median length of hospital stay (days) & 10 & 9 & 17 & $<0.001$ \\
\hline Min (days) & 3 & 3 & 8 & \\
\hline Max (days) & 27 & 26 & 27 & \\
\hline IQR (days) & $7-15$ & $5-12$ & $14-21$ & \\
\hline Median length of postoperative hospital stay (days) & n.a. & n.a. & 9 & \\
\hline Patients with general complications; $n(\%)$ & $11 / 58(19.0)$ & $8 / 45(17.8)$ & $3 / 13(23.1)$ & 0.69 \\
\hline Urinary tract infection; $n$ & 6 & 3 & 3 & 0.12 \\
\hline Pneumonia; $n$ & 4 & 4 & 0 & 1 \\
\hline Bedsore; $n$ & 1 & 1 & 0 & 1 \\
\hline Patients with surgery-related complications; $n(\%)$ & n.a. & n.a. & $2(15.4)$ & \\
\hline Implant malposition; $\mathrm{n}$ & & & 2 & \\
\hline Surgical revision; $n(\%)$ & n.a. & n.a. & $0(0.0)$ & \\
\hline Secondary operative treatment; $n(\%)$ & n.a. & $4(8.9)$ & n.a & \\
\hline One-year mortality rate; $\%$ & 13.7 & 14.5 & 7.3 & 0.548 \\
\hline \multicolumn{5}{|l|}{ Living environment at $\mathbf{t} 4 ; n(\%)$} \\
\hline Home & $32(84.2)$ & $23(85.2)$ & $9(81.8)$ & 0.5 \\
\hline Nursing home & $5(13.2)$ & $4(14.8)$ & $1(9.1)$ & 0.5 \\
\hline Hospital & $1(2.6)$ & $0(0.0)$ & $1(9.1)$ & $0-5$ \\
\hline New osteoporotic fracture between $\mathrm{t} 2$ and $\mathrm{t} 4 ; n(\%)$ & $6(15.8)$ & $2(5.1)$ & $4(30.8)$ & 0.0286 \\
\hline Re-hospitalization between $\mathrm{t} 2$ and $\mathrm{t} 4 ; n(\%)$ & $15(39.5)$ & $16(43.7)$ & $5(41.7)$ & 0.721 \\
\hline
\end{tabular}

n.a. not applicable, $p$ values below 0.05 are depicted in bold 
Table 7 Patient-reported outcomes of conservatively $(n=45)$ and operatively $(n=14)$ treated patients with FFP type II during the course of the observation period

\begin{tabular}{|c|c|c|c|c|c|}
\hline & Before trauma & $\mathrm{t} 1$ & $\mathrm{t} 2$ & $\mathrm{t} 3$ & $\mathrm{t} 4$ \\
\hline \multicolumn{6}{|c|}{ Patients living at home independently or with assistance (\%) } \\
\hline $\begin{array}{l}\text { FFP type II conserva- } \\
\text { tive }\end{array}$ & 86.7 & n.a. & 40 & 78.8 & 85.2 \\
\hline FFP type II operative & 85.7 & n.a. & 53.8 & 91.7 & 81.8 \\
\hline \multicolumn{6}{|c|}{ Short Form-8 Physical Component Score (median) } \\
\hline $\begin{array}{l}\text { FFP type II conserva- } \\
\text { tive }\end{array}$ & 42.05 & n.a. & 24.13 & 35.22 & 35.08 \\
\hline FFP type II operative & 38.39 & n.a. & 21.66 & 27.48 & 39.63 \\
\hline \multicolumn{6}{|c|}{ Short Form-8 Mental Component Score (median) } \\
\hline $\begin{array}{l}\text { FFP type II conserva- } \\
\text { tive }\end{array}$ & 57.25 & n.a. & 52.2 & 57.6 & 57.08 \\
\hline FFP type II operative & 52.68 & n.a. & 57.13 & 57.54 & 59.78 \\
\hline \multicolumn{6}{|c|}{ European Quality of Life - 5 Dimensions - 5 Levels (median) } \\
\hline $\begin{array}{l}\text { FFP type II conserva- } \\
\text { tive }\end{array}$ & 0.9 & 0.23 & 0.35 & 0.77 & 0.72 \\
\hline FFP type II operative & 0.76 & 0.21 & 0.38 & 0.91 & 0.74 \\
\hline \multicolumn{6}{|c|}{ Patients walking independently (\%) } \\
\hline $\begin{array}{l}\text { FFP type II conserva- } \\
\text { tive }\end{array}$ & n.a. & 28.9 & 4.4 & 36.4 & 29.6 \\
\hline FFP type II operative & n.a. & 7.1 & 7.7 & 8.3 & 27.3 \\
\hline \multicolumn{6}{|l|}{ Barthel index (median) } \\
\hline $\begin{array}{l}\text { FFP type II conserva- } \\
\text { tive }\end{array}$ & n.a. & 45 & 60 & 85 & 85 \\
\hline $\begin{array}{l}\text { FFP type II operative } \\
\text { arker Mobility Score (m }\end{array}$ & $\begin{array}{r}n . a . \\
\text { dian) }\end{array}$ & 42.5 & 65 & 85 & 95 \\
\hline $\begin{array}{l}\text { FFP type II conserva- } \\
\text { tive }\end{array}$ & n.a. & 1 & 2 & 4 & 5 \\
\hline FFP type II operative & n.a. & 1 & 2 & 5 & 6 \\
\hline \multicolumn{6}{|c|}{ Numeric Rating Scale on load (median) } \\
\hline $\begin{array}{l}\text { FFP type II conserva- } \\
\text { tive }\end{array}$ & n.a. & 10 & 8 & 2.5 & 0 \\
\hline FFP type II operative & n.a. & 7.5 & 5 & 5 & 3 \\
\hline
\end{tabular}

n.a. not available

consequence of a longer $\operatorname{LoS}(p<0.001)$. General in-hospital complications were slightly higher in the operative group without significant difference with the conservative group $(p=0.69)$. One year after primary presentation ( $\mathrm{t} 4)$, the EQ5D-5L and SF-8 MCS scores were similar between the conservative and the operative group, whereas the SF-8 PCS and Barthel index were better for the operative group. One-year mortality rate of the operated patients $(7.3 \%)$ was only half the value of the conservative group (14.5\%), although not significant $(p=0.548)$. These data suggest that patients with FFP type II, who present later in a reduced clinical condition should be operated early after hospital admission. Data from selected outcome scores show that they recover better than their conservatively treated counterparts.
Also, in patients with FFP type III and type IV, surgical treatment proved to be safe and beneficial. All but one patient with FFP type III have been treated operatively. There were no surgery-related complications. One-year mortality rate was $6.7 \%$, which is lower than in patients with FFP type III in the retrospective series of Rommens et al. [23]. At t4, the median values of EQ-5D-5L and SF-8 PCS nearly reached the level before FFP. The median scores of the Barthel index and the PMS, the level of autonomy and the rate of patients returning home improved steadily over time and were the highest at $t 4$. Patients with FFP type IV had an equivalent course. It is remarkable that the operative group within the patients with FFP type IV was admitted in hospital only 6 weeks after the beginning of complaints. $45.8 \%$ of them did not remember a traumatic event. We believe that these patients primarily suffered a FFP with a lower level of instability. In the weeks before admission, insidious fracture progression led to FFP type IV [26]. The time period before hospital admission can be regarded as a period of unsuccessful conservative treatment. The median values of EQ-5D-5L and SF-8 PCS increased after operative treatment to reach their highest values at 4 . Similarly, all other scores increased over time and were the highest at $t 4$. One-year mortality was rate was $9.1 \%$, which is comparably low as in operated patients with FFP type II and FFP type III. This data support operative treatment in these subgroups of patients with the highest degrees of pelvic instability.

This is the first study, which prospectively assesses conditions, which influence outcome after FFP. Consequently, data are not completely comparable with other published series [7, 23, 24, 27, 28]. Several studies find a longer $\operatorname{LoS}$ in operatively treated patients: 16.3 days for the operative versus 8.9 days for the conservative group in the series of Oberkircher et al. [15]; 8.9 days for the conservative group, 16.6 days for the patients with percutaneous and 19,3 days for the patients with open surgical procedures in the series of Gericke et al. [24]; 12.7 days for the non-operative versus 23.6 days for the operative group in the series of Schmitz et al. [29]. The rate of general in-hospital complications is important in all series with a tendency for a higher rate in the operative group. Gericke et al. mention $21.8 \%$ in the conservative group, $28.4 \%$ in the percutaneous and $33.0 \%$ in the open surgery group [24]. Schmitz et al. mention $18 \%$ for the conservative versus $34 \%$ for the operative group [29]. Osterhoff et al. calculated $34.5 \%$ for the operative versus $17.1 \%$ for the conservative group [9]. Schuetze et al. presented a rate of $21.5 \%$ in a purely operatively treated group of 116 patients [30]. One-year mortality rate in our study population was lower than in all other series, although higher than in the reference population [31].

A remarkable finding was that $57.3 \%$ of our patients were diagnosed with osteoporosis and $36.4 \%$ already suffered another osteoporotic fracture before FFP. Only 34.5\% 
Table 8 Demographics and selected data of operatively treated patients with FFP type III and FFP type IV during the course of the observation period

\begin{tabular}{|c|c|c|}
\hline & FFP type III operative & FFP type IV operative \\
\hline Number & 10 & 24 \\
\hline Mean age (years) & 77.7 & 75.8 \\
\hline Standard deviation (SD) & 12.9 & 8.6 \\
\hline Women; $n(\%)$ & $10(100.0)$ & $24(100.0)$ \\
\hline Patients with comorbidities; $n(\%)$ & $10(100.0)$ & $19(79.2)$ \\
\hline Patients with two comorbidities or more; $n(\%)$ & $6(60.0)$ & $13(54.2)$ \\
\hline Osteoporosis in medical history; $n(\%)$ & $4(40.0)$ & $16(66.7)$ \\
\hline Previous osteoporotic fracture, $n(\%)$ & $3(30.0)$ & $10(41.7)$ \\
\hline Patients with more than 5 different drugs per day; $n(\%)$ & $6(60.0)$ & $17(70.8)$ \\
\hline Anti-resorptive medication; $n(\%)$ & $1(10.0)$ & $12(50.0)$ \\
\hline \multicolumn{3}{|l|}{ Living situation before admission; $n(\%)$} \\
\hline Independently & $9(90.0)$ & $20(83.3)$ \\
\hline Assisted living & $0(0.0)$ & $1(4.2)$ \\
\hline Nursing home & $1(10.0)$ & $1(4.2)$ \\
\hline Hospital & $0(0.0)$ & $2(8.4)$ \\
\hline \multicolumn{3}{|l|}{ Trauma mechanism; $n(\%)$} \\
\hline Fall from standing position & $7(70.0)$ & $10(41.7)$ \\
\hline Recurrent falls & $1(10.0)$ & $3(12.5)$ \\
\hline No trauma memorable & $2(20.0)$ & $11(45.8)$ \\
\hline \multicolumn{3}{|c|}{ Time between trauma or beginning of complaints and t1 (days) } \\
\hline Median & 6.5 & 41 \\
\hline Min & 0 & 0 \\
\hline Max & 252 & 361 \\
\hline Median length of hospital stay (days) & 14 & 14 \\
\hline Min (days) & 9 & 7 \\
\hline Max (days) & 28 & 30 \\
\hline IQR (days) & $10.25-17$ & $9-20$ \\
\hline Median length of postoperative hospital stay (days) & 9 & 8.5 \\
\hline Patients with general complications; $n(\%)$ & $4(40.0)$ & $9(37.5)$ \\
\hline Urinary tract infection; $n$ & 3 & 7 \\
\hline Pneumonia; $n$ & 0 & 4 \\
\hline Bedsore; $n$ & 2 & 0 \\
\hline Patients with surgery-related complications; $n(\%)$ & $0(0.0)$ & \\
\hline Implant malposition with paresis; $n$ & & 1 \\
\hline Plate breakage & $2(8.3)$ & 1 \\
\hline Revision surgery; $n(\%)$ & $0(0.0)$ & $1(4.2)$ \\
\hline ne-year mortality rate; $\%$ & 6.7 & 9.1 \\
\hline \multicolumn{3}{|l|}{ Living environment at t4; $n(\%)$} \\
\hline Home & $8(100.0)$ & $19(95.0)$ \\
\hline Nursing home & & $1(5.0)$ \\
\hline New osteoporotic fracture between t 2 and t $4 ; n(\%)$ & $0(0.0)$ & $3(13.6)$ \\
\hline Re-hospitalization rate between $\mathrm{t} 2$ and $\mathrm{t} 4 ; n(\%)$ & $2(20.0)$ & $8(35.2)$ \\
\hline
\end{tabular}

n.a. not available

had antiresorptive medication. In the first year after hospitalization, $14.7 \%$ suffered another osteoporotic fracture. These data support our view that FFP must be regarded as an index fracture for osteoporosis and start or continuation of anti-osteoporosis therapy is needed in all these patients [32].

This study has several limitations. Although prospective, this is not randomized. Statistical comparison was 
Table 9 Patient-reported outcomes of patients with FFP type III and type IV during the course of the observation period

\begin{tabular}{|c|c|c|c|c|c|}
\hline & Before trauma & $\mathrm{t} 1$ & $\mathrm{t} 2$ & $\mathrm{t} 3$ & $\mathrm{t} 4$ \\
\hline \multicolumn{6}{|c|}{ Patients living at home independently or with assistance (\%) } \\
\hline FFP type III & 90 & n.a. & 30 & 70 & 100 \\
\hline FFP type IV & 87.5 & n.a. & 45.8 & 91.3 & 95 \\
\hline \multicolumn{6}{|c|}{ Short Form-8 Physical Component Score (median) } \\
\hline FFP type III & 44.93 & n.a. & 22.99 & 33.53 & 36.9 \\
\hline FFP type IV & 27.53 & n.a. & 25.39 & 31.23 & 39.35 \\
\hline \multicolumn{6}{|c|}{ Short Form-8 Mental Component Score (median) } \\
\hline FFP type III & 58.05 & n.a. & 63.7 & 56.49 & 54.28 \\
\hline FFP type IV & 56.13 & n.a. & 52.95 & 54.79 & 53.79 \\
\hline \multicolumn{6}{|c|}{ European Quality of Life - 5 Dimensions - 5 Levels (median) } \\
\hline FFP type III & 0.88 & 0.16 & 0.18 & 0.39 & 0.55 \\
\hline FFP type IV & 0.87 & 0.1 & 0.38 & 0.73 & 0.74 \\
\hline \multicolumn{6}{|c|}{ Patients walking independently (\%) } \\
\hline FFP type III & n.a. & 10.0 & 0.0 & 10.0 & 37.5 \\
\hline FFP type IV & n.a. & 16.7 & 8.9 & 21.7 & 30.0 \\
\hline \multicolumn{6}{|c|}{ Barthel index (median) } \\
\hline FFP type III & n.a. & 37.5 & 55 & 67.5 & 85 \\
\hline FFP type IV & n.a. & 45 & 77.5 & 90 & 95 \\
\hline \multicolumn{6}{|c|}{ Parker Mobility Score (median) } \\
\hline FFP type III & n.a. & 1 & 1 & 4 & 5 \\
\hline FFP type IV & n.a. & 2 & 2 & 5 & 6.50 \\
\hline \multicolumn{6}{|c|}{ Numeric Rating Scale on load (median) } \\
\hline FFP type III & n.a. & 10 & 7.5 & 3.50 & 4 \\
\hline FFP type IV & n.a. & 10 & 5 & 5 & 6 \\
\hline
\end{tabular}

n.a. not available
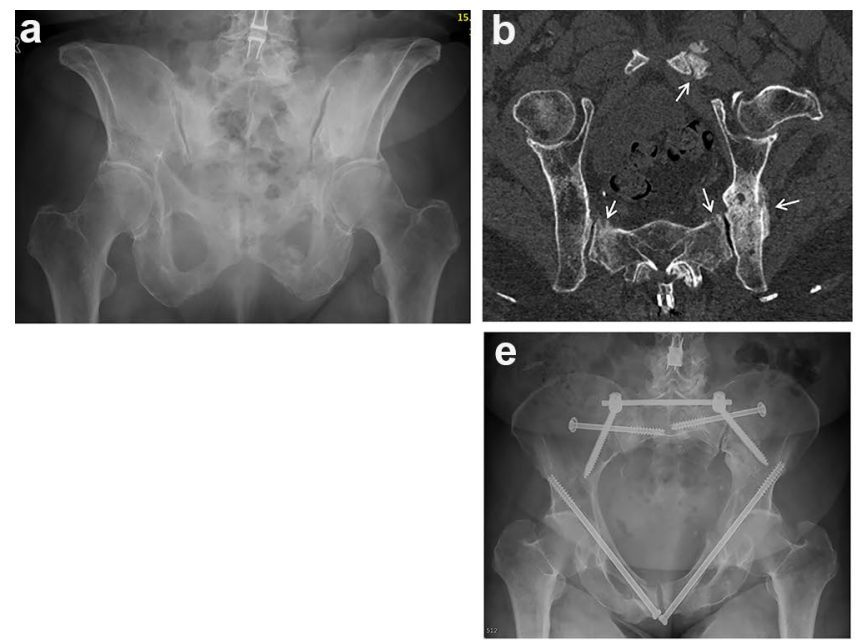

Fig. 3 a-f A seventy-three-year-old female suffered of chronic pain in the pelvic region after a fall. There has been a conservative treatment for several months with pain therapy and mobilization. The a.p. pelvic overview after 6 months shows bilateral anterior pubic rami fractures with callus formation but without healing (a). The CTreconstruction in the plane of the pelvic brim showed bilateral sacral ala fractures, a healed left posterior ilium fracture and a left-sided anterior instability (arrows) (b). Coronal CT-cut through the anterior only possible in some subgroups. After 1 year, there was a drop-out of more than $25 \%$ due to mortality, change of treatment, lost to follow-up or refusal of further participation in the study. Due to its specific study design, data cannot completely be compared with those of recent retrospective or prospective studies. Multicenter, prospective randomized studies are needed to collect more specific data on outcome of different treatment algorithms and find the best indications for operative treatment.

\section{Conclusion}

Conservative treatment is reasonable and successful in patients with a lower degree of pelvic instability, who are hospitalized immediately after trauma. Key factors in favor of surgical treatment are fracture types with a higher degree of pelvic instability, patients with delayed presentation and who are in reduced clinical condition due to FFP at the time of hospital admission. Surgical treatment can be regarded as safe and reliable. Conversion from conservative to operative therapy is advisable when patients do not recover quickly. Minimal-invasive surgical stabilization is connected with an acceptable rate of in-hospital complications and a low rate of surgery-related complications. Operative treatment is connected with longer hospital stay. Outcome of surgical therapy is favorable. Specific functional and patient-related scores improve over time to be the highest 1 year after primary admission. Mortality in the operative patients is the
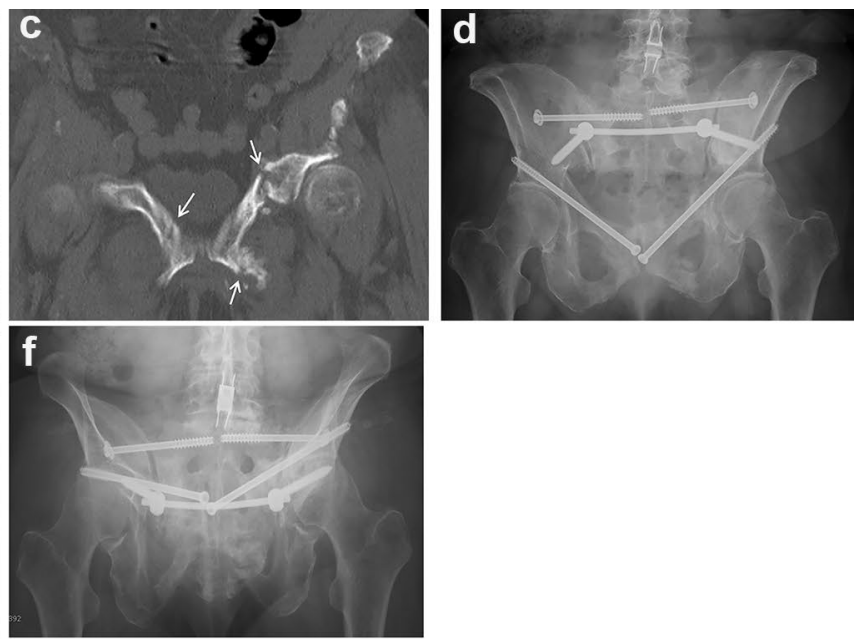

pelvic ring showed bilateral anterior pubic rami fractures with callus formation but without healing (arrows) (c). These fractures corresponded with a FFP type IVc. Postoperative a.p. pelvic overview (d). The posterior instabilities were fixed with a transiliac internal fixator and bilateral iliosacral screws in S1. There was not enough place for safe placement of a transsacral bar in S1. The anterior instabilities were transfixed with two retrograde transpubic screws. Postoperative pelvic inlet view (e). Postoperative pelvic outlet view (f) 
lowest in the operative group. These data support the recommendations of Rommens and Hofmann, published in their classification paper.

Acknowledgements We sincerely thank Mrs. Kirsten Schuelke for meticulous data collection.

Funding Open Access funding enabled and organized by Projekt DEAL. This research was funded by the Zimmer-Biomet Company, Sulzerallee 6, PO Box CH-9404 Winterthur, Switzerland, Grant No. IRE 2017-56CH.

\section{Declarations}

Conflict of interest The authors declare that they have no conflict of interest.

Open Access This article is licensed under a Creative Commons Attribution 4.0 International License, which permits use, sharing, adaptation, distribution and reproduction in any medium or format, as long as you give appropriate credit to the original author(s) and the source, provide a link to the Creative Commons licence, and indicate if changes were made. The images or other third party material in this article are included in the article's Creative Commons licence, unless indicated otherwise in a credit line to the material. If material is not included in the article's Creative Commons licence and your intended use is not permitted by statutory regulation or exceeds the permitted use, you will need to obtain permission directly from the copyright holder. To view a copy of this licence, visit http://creativecommons.org/licenses/by/4.0/.

\section{References}

1. Vuillemin N, Pape HC, Rommens PM, Lippuner K, Siebenrock KA, Keel MJ, Bastian JD. A bibliometric analysis of fragility fractures: top 50. Medicina (Kaunas). 2021;57(6):639. https:// doi.org/10.3390/medicina57060639.PMID:34205638;PMCID: PMC8233744.

2. Breuil V, Roux CH, Testa J, Albert C, Chassang M, Brocq O, Euller-Ziegler L. Outcome of osteoporotic pelvic fractures: an underestimated severity Survey of 60 cases. Jt Bone Spine. 2008;75(5):585-8. https://doi.org/10.1016/j.jbspin.2008.01.024 (Epub 2008 May 12 PMID: 18474446).

3. Andrich S, Haastert B, Neuhaus E, Neidert K, Arend W, Ohmann C, Grebe J, Vogt A, Jungbluth P, Rösler G, Windolf J, Icks A. Epidemiology of pelvic fractures in germany: considerably high incidence rates among older people. PLoS ONE. 2015;10(9): e0139078. https://doi.org/10.1371/journal.pone.0139078.PMID: 26418971;PMCID:PMC4587805.

4. Rommens PM, Wagner D, Hofmann A. Fragility fractures of the pelvis. JBJS Rev. 2017. https://doi.org/10.2106/JBJS.RVW.16. 00057 (PMID: 28359073).

5. Linstrom NJ, Heiserman JE, Kortman KE, Crawford NR, Baek S, Anderson RL, Pitt AM, Karis JP, Ross JS, Lekovic GP, Dean $\mathrm{BL}$. Anatomical and biomechanical analyses of the unique and consistent locations of sacral insufficiency fractures. Spine (Phila Pa 1976). 2009;34(4):309-15. https://doi.org/10.1097/BRS.0b013 e318191ea01.PMID:19214089;PMCID:PMC2709278.

6. Eckardt H, Egger A, Hasler RM, Zech CJ, Vach W, Suhm N, Morgenstern M, Saxer F. Good functional outcome in patients suffering fragility fractures of the pelvis treated with percutaneous screw stabilisation: assessment of complications and factors influencing failure. Injury. 2017;48(12):2717-23. https://doi. org/10.1016/j.injury.2017.11.002 (Epub 2017 Nov 4 PMID: 29122281).

7. Yoshida M, Tajima K, Saito Y, Sato K, Uenishi N, Iwata M. Mobility and mortality of 340 patients with fragility fracture of the pelvis. Eur J Trauma Emerg Surg. 2021;47(1):29-36. https:// doi.org/10.1007/s00068-020-01481-3 (Epub 2020 Aug 28 PMID: 32860102)

8. Hack J, Buecking B, Strauch L, Lenz J, Knauf T, Ruchholtz S, Oberkircher L. Self-rated health status and activities of daily living in the first 12 months after fragility fractures of the pelvis-a prospective study on 134 patients. Osteoporos Int. 2021. https:// doi.org/10.1007/s00198-021-06104-0.

9. Osterhoff G, Noser J, Held U, Werner CML, Pape HC, Dietrich M. Early operative versus nonoperative treatment of fragility fractures of the pelvis: a propensity-matched multicenter study. J Orthop Trauma. 2019;33(11):e410-5. https://doi.org/10.1097/BOT.00000 00000001584 (PMID: 31633644).

10. Rommens PM, Hofmann A, Kraemer S, Kisilak M, Boudissa M, Wagner D. Operative treatment of fragility fractures of the pelvis: a critical analysis of 140 patients. Eur J Trauma Emerg Surg. 2021. https://doi.org/10.1007/s00068-021-01799-6.

11. Wagner D, Kisilak M, Porcheron G, Krämer S, Mehling I, Hofmann A, Rommens PM. Trans-sacral bar osteosynthesis provides low mortality and high mobility in patients with fragility fractures of the pelvis. Sci Rep. 2021;11(1):14201. https://doi.org/10.1038/ s41598-021-93559-0.PMID:34244526;PMCID:PMC8270908.

12. Rommens PM, Hofmann A. Comprehensive classification of fragility fractures of the pelvic ring: recommendations for surgical treatment. Injury. 2013;44(12):1733-44. https://doi.org/10.1016/j. injury.2013.06.023 (Epub 2013 Jul 18 PMID: 23871193).

13. Pieroh P, Höch A, Hohmann T, Gras F, Märdian S, Pflug A, Wittenberg S, Ihle C, Blankenburg N, Dallacker-Losensky K, Schröder T, Herath SC, Wagner D, Palm HG, Josten C, Stuby FM. Fragility fractures of the pelvis classification: a multicenter assessment of the intra-rater and inter-rater reliabilities and percentage of agreement. J Bone Jt Surg Am. 2019;101(11):987-94. https://doi.org/10.2106/JBJS.18.00930 (PMID: 31169575).

14. Höch A, Pieroh P, Henkelmann R, Josten C, Böhme J. In-screw polymethylmethacrylate-augmented sacroiliac screw for the treatment of fragility fractures of the pelvis: a prospective, observational study with 1-year follow-up. BMC Surg. 2017;17(1):132. https://doi.org/10.1186/s12893-017-0330-y.PMID:29221479; PMCID:PMC5723042.

15. Oberkircher L, Lenz J, Bücking B, Eschbach D, Aigner R, Bliemel C, Schoeneberg C, Ruchholtz S, Hack J. Which factors influence treatment decision in fragility fractures of the pelvis?-results of a prospective study. BMC Musculoskelet Disord. 2021;22(1):690. https://doi.org/10.1186/s12891-021-04573-2.PMID:34388997; PMCID:PMC8364046.

16. Beierlein V, Morfeld M, Bergelt C, Bullinger M, Brähler E. Messung der gesundheitsbezogenen Lebensqualität mit dem SF-8. Deutsche Normdaten aus einer repräsentativen schriftlichen Befragung. Diagnostica. 2012;58(3):145-53.

17. Gusi N, Olivares P, Rajendram R. The EQ-5D health-related quality of life questionnaire. In: Preedy VR, Watson R, editors. Handbook of Disease Burdens and Quality of Life Measures. New York: Springer; 2010. p. 87-99.

18. (2015) EQ-5D-3L user guide.

19. Mahoney FI, Barthel DW. Functional evaluation: the Barthel index. MD State Med J. 1965;14:61-5.

20. Parker M, Palmer C. A new mobility score for predicting mortality after hip fracture. J Bone Jt Surg Br. 1993;75-B(5):797-8. https:// doi.org/10.1302/0301-620X.75B5.8376443 (PMID: 8376443). 
21. Rodriguez CS. Pain measurement in the elderly: a review. Pain Manag Nurs. 2001;2:38-46. https://doi.org/10.1053/jpmn.2001. 23746 (PMID: 11706769).

22. Oberkircher L, Ruchholtz S, Rommens PM, Hofmann A, Bücking B, Krüger A. Osteoporotic pelvic fractures. Dtsch Arztebl Int. 2018;115(5):70-80. https://doi.org/10.3238/arztebl.2018.0070. PMID:29439771;PMCID:PMC5817189.

23. Rommens PM, Boudissa M, Krämer S, Kisilak M, Hofmann A, Wagner D. Operative treatment of fragility fractures of the pelvis is connected with lower mortality. A single institution experience. PLoS ONE. 2021;16(7): e0253408. https://doi.org/10.1371/journ al.pone. 0253408 .

24. Gericke L, Fritz A, Osterhoff G, Josten C, Pieroh P, Höch A. Percutaneous operative treatment of fragility fractures of the pelvis may not increase the general rate of complications compared to non-operative treatment. Eur J Trauma Emerg Surg. 2021. https:// doi.org/10.1007/s00068-021-01660-w.

25. Höch A, Pieroh P, Gras F, Hohmann T, Märdian S, Holmenschlager F, Keil H, Palm HG, Herath SC, Josten C, Schmal H, Stuby FM, Pelvic Injury Register of the German Trauma Society. Age and "general health"-beside fracture classification-affect the therapeutic decision for geriatric pelvic ring fractures: a German pelvic injury register study. Int Orthop. 2019;43(11):2629-36. https://doi.org/10.1007/s00264-019-04326-w.

26. Rommens PM, Arand C, Hopf JC, Mehling I, Dietz SO, Wagner D. Progress of instability in fragility fractures of the pelvis: an observational study. Injury. 2019;50(11):1966-73. https://doi. org/10.1016/j.injury.2019.08.038 (Epub 2019 Aug 27 PMID: 31492514).

27. Banierink H, Ten Duis K, de Vries R, Wendt K, Heineman E, Reininga I, IJpma F. Pelvic ring injury in the elderly: fragile patients with substantial mortality rates and long-term physical impairment. PLoS ONE. 2019;14(5):e0216809. https://doi.org/ 10.1371/journal.pone.0216809.

28. Maier GS, Kolbow K, Lazovic D, Horas K, Roth KE, Seeger JB, Maus U. Risk factors for pelvic insufficiency fractures and outcome after conservative therapy. Arch Gerontol Geriatr. 2016;67:80-5. https://doi.org/10.1016/j.archger.2016.06.020.

29. Schmitz P, Lüdeck S, Baumann F, Kretschmer R, Nerlich M, Kerschbaum M. Patient-related quality of life after pelvic ring fractures in elderly. Int Orthop. 2019;43(2):261-7. https://doi.org/10. 1007/s00264-018-4030-8 (Epub 2018 Jun 26 PMID: 29946740).

30. Schuetze K, Eickhoff A, Dehner C, Blidon A, Gebhard F, Richter PH. Short-term outcome of fragility fractures of the pelvis in the elderly treated with screw osteosynthesis and external fixator. Eur J Trauma Emerg Surg. 2021. https://doi.org/10.1007/ s00068-021-01780-3.

31. https://www.statistik.rlp.de/fileadmin/dokumente/berichte/A/ 2033/A2033_201600_1j_L.pdf

32. Rommens PM, Drees P, Thomczyk S, Betz U, Wagner D, Hofmann A. The fragility fracture of the pelvis is a fracture indicating osteoporosis. Osteologie. 2018;27:144-53.

\section{Authors and Affiliations}

\section{Pol Maria Rommens ${ }^{1} @$. Johannes Christoph Hopf ${ }^{1} \cdot$ Charlotte Arand $^{1} \cdot$ Kristin Handrich $^{1} \cdot$ Mehdi Boudissa $^{1}$. Daniel Wagner ${ }^{1}$}

Pol Maria Rommens

prommens@uni-mainz.de

Johannes Christoph Hopf

Johannes.Hopf@unimedizin-mainz.de

Charlotte Arand

Charlotte.Arand@unimedizin-mainz.de

Kristin Handrich

Kristin.handrich@unimedizin-mainz.de
Mehdi Boudissa

mehdicale@gmail.com

Daniel Wagner

Wagner.daniel@gmx.ch

1 Department of Orthopaedics and Traumatology, University Medical Center, Langenbeckstrasse 1, 55131 Mainz, Germany 